\title{
Videostroboscopic Evaluation of the Vocal Cords before and after Microlaryngeal Phonosurgery for Benign Lesions
}

\author{
Yasir Lafta Hassoun ${ }^{1^{*}}$, Karrar Mohsin Shaheed $^{2}$ and Ehsan Hameed Al-Turaihy ${ }^{3}$ \\ ${ }^{1}$ Professor in Otolaryngology/College of Medicine/Kufa University/Iraq, Consultant Otolaryndologist /Al-Sadr Medical City \\ ${ }^{2}$ Arabic Board postgraduate student/Najaf center, Iraq \\ ${ }^{3}$ Otolaryngology specialist /AI-Sadr Medical City, Iraq
}

Received 06 Nov 2017, Accepted 07 Jan 2018, Available online 11 Jan 2018, Vol.6 (Jan/Feb 2018 issue)

\begin{abstract}
Background: Benign vocal lesions are common clinical and surgical problems affecting individuals with high vocal demand. These lesions are assessed and treated in different ways. Good phonatory function can be achieved by proper diagnosis, perfect surgical technique and good voice rehabilitation. Videostroboscopy is an important tool to assess the dynamic properties of vocal cord mucosa, the phonatory functional part.

Study design: Prospective cross-sectional study.

Objectives: To evaluate the postoperative results of microlaryngeal phonosurgery by the use of videostroposcopy.

Method: Twenty patients with benign vocal lesions were included and studied. Videostroboscopic examination was undertaken preoperatively, one week and one month postoperatively.

Results and discussion: There were significant differences of videostroboscopic parameters between preoperative and postoperative examinations; there was an improvement in most of these parameters one week after surgery, except for, closure pattern and duration of closure where they had been shown to be improved one month after surgery.

Conclusion: Videostroboscopy is an excellent tool to assess and understand vocal cord mucosal vibration changes before and after microlaryngeal phonosurgery and recommended to be used in routine outpatient examination of patients with benign vocal lesions especially those who required surgical treatment.
\end{abstract}

Keywords: Videostroboscopy, benign vocal cord lesions, phonation, microlaryngeal phonosurgery

\section{Introduction}

Vocal cord anatomy, the color of mucosa, the gross movements and vocal cord lesions can be evaluated by traditional laryngoscopic procedures but evaluation of vocal cord vibration requires special imaging technology to "slow down" vibration for assessment. At this time, the most widely used technique for assessing the vibratory characteristics of the vocal cords is videostroboscopy. To assess vibration patterns during phonation, where the fundamental frequency (FO) of vocal cord vibration is typically more than 100 cycles per second $(\mathrm{Hz})$, vibration must be observed in slow motion or in what appears to be slow motion. Videostroboscopy is used clinically to approximate slow motion for laryngeal and voice evaluation [1]. Oertel was initially introduced stroboscope in 1878 [2]. In 1950s, laryngeal stroboscopy became essentially more feasible with acoustically synchronized light flashes illustrated by Timcke's device. Timcke and his co-authors demonstrated that the electronic laryngosynchro-stroboscope was clinically more valuable compared with the older device. [3],[4]

*Corresponding author's ORCID ID: 0000-0001-6746-1512

DOI: https://doi.org/10.14741/ijmcr.v6i01.10907
Videostroboscopy allows evaluation of the following vibratory parameters; symmetry, phase closure, amplitude, glottic configuration and mucosal wave. [5]

The mucosal cover of most of the upper airway is respiratory epithelium, with numerous mucous glands. Over the free edge of the vocal cord, however; mucosa is adapted for periodic vibration with squamous epithelium and no mucous glands. A highly specialized lamina propria separates the epithelium from underlying muscle. The superficial layer of the lamina propria is often referred to as Reinke's space, although it is not actually a potential space. This Reinke's space is usual origin for the benign lesions of the vocal cords. [6]

Sound is produced by the larynx when expiratory airflow induces vibration of free edges of the vocal cords as a result of the interaction of aerodynamic and myoelastic forces. Five conditions must be met to support normal phonation: appropriate vocal cord approximation, adequate expiratory force, sufficient vibratory capacity of the vocal cords, favorable vocal cord contour and volitional control of vocal cord length and tension [5]. The dynamic changes on the free margin of the vocal cord are easily noticed and video-recorded by the strobos.

59|Int. J. of Multidisciplinary and Current research, Vol.6 (Jan/Feb 2018) 
Several benign pathological entities affecting the vocal cord; including polyps, nodules, cysts, Reinke's edema, vocal sulcus and vascular lesions; causing significant dysphonia. Some of these lesions respond to conservative treatment; vocal hygiene, good hydration and antireflux measures; and many need to be treated surgically. [7]

\section{Patients and methods}

This prospective cross-sectional study had been performed in Al-Sadr medical city in Najaf / Iraq during the period between March 2015 and March 2016. Twenty patients had been included in the study; they were complaining of hoarseness, laryngoscopic examination revealed the evidence of benign vocal cord lesion, including polyps, cysts and nodules when voice therapy and medical measures fail to cure the condition. Patients with malignant conditions and those with laryngeal paralysis, patients with laryngeal pathologies not including the vocal cords and patients younger than 18 years were excluded. Videostroboscopic examination, using 70 degree rigid endoscope connected to ATMOS Servant S61 strobe unit, done for them preoperatively. They underwent microlaryngeal resection of the lesion. Patients were followed by laryngoscopy and videostroboscopy one week and one month postoperatively. The stroboscopic picture was analyzed to note:
- Mucosal wave; present or absent.

- Symmetry of the mucosal wave; symmetrical wave or asymmetrical.

- Amplitude of vibration; normal or decreased or increased.

- Nonvibratory segment; whether present or not.

- Periodicity of the mucosal wave.

- Duration of closure ; either half, predominately open or open allover

- Pattern of closure; closed, anterior chink, posterior chink, hourglass-shaped, spindle-shaped or irregular closure.

Statistical analysis was done by using SPSS (statistical package for social sciences) version 20 . The data were presented as frequency and percentage. We used chi square for categorical data. We set $P$ value $\leq 0.05$ as significant.

\section{Results}

A total of 20 patients had been included in this study. There were 2 patients with bilateral lesions. They were aged above eighteen years, ranging from nineteen through fifty years old (peak age 36-45 years), other demographic facts are shown in table (1).

Table 1 Demographic characteristics of the studied sample

\begin{tabular}{|c|c|c|c|}
\hline Variable & & Frequency & Percentage \\
\hline \multirow{4}{*}{ Age in years } & $18-20$ & 2 & 10 \\
\cline { 2 - 4 } & $21-30$ & 5 & 25 \\
\cline { 2 - 4 } & $31-40$ & 5 & 25 \\
\cline { 2 - 4 } & $>41$ & 8 & 40 \\
\hline \multirow{3}{*}{ Gender } & Male & 8 & 40 \\
\cline { 2 - 4 } & Female & 12 & 60 \\
\cline { 2 - 4 } & House wife & 10 & 50 \\
\cline { 2 - 4 } & Teacher & 6 & 30 \\
\hline \multirow{3}{*}{ Smoking } & Others & 4 & 20 \\
\cline { 2 - 4 } & Yes & 5 & 75 \\
\hline \multirow{2}{*}{ GERD } & No & 9 & 45 \\
\cline { 2 - 4 } & Yes & 11 & 55 \\
\hline Hoarsness & No & 20 & 100 \\
\hline \multirow{2}{*}{$\begin{array}{c}\text { Type of lesion } \\
\text { "22 vocal cords" }\end{array}$} & Yes & 18 & 91.8 \\
\cline { 2 - 4 } & Polyp & 2 & 9.1 \\
\cline { 2 - 4 } & Nodule & 10 & 45.5 \\
\hline Side of lesion & Cyst & 12 & 54.5 \\
\cline { 2 - 4 } & Right 22 vocal cords" & Left & \\
\cline { 2 - 4 } & & & 25 \\
\hline
\end{tabular}

Table2 Association between type of the lesion and postoperative result

\begin{tabular}{|c|c|c|c|c|c|}
\hline & & \multicolumn{3}{|c|}{ Postoperative endoscopy } & \multirow{2}{*}{$P$ value } \\
\hline & & Incomplete removal & Irregular scar & Normal & \\
\hline \multirow{6}{*}{$\begin{array}{l}\text { Type of lesion } \\
\text { preoperative }\end{array}$} & \multirow{2}{*}{ Cyst } & 0 & 0 & 2 & \multirow{6}{*}{$<0.001$} \\
\hline & & $0.0 \%$ & $0.0 \%$ & $100.0 \%$ & \\
\hline & \multirow{2}{*}{ Nodule } & 0 & 2 & 0 & \\
\hline & & $0.0 \%$ & $100.0 \%$ & $0.0 \%$ & \\
\hline & \multirow{2}{*}{ Polyp } & 2 & 0 & 16 & \\
\hline & & $11.1 \%$ & $0.0 \%$ & $88.9 \%$ & \\
\hline \multirow{2}{*}{\multicolumn{2}{|c|}{ Total }} & 2 & 2 & 18 & \\
\hline & & $9.1 \%$ & $9.1 \%$ & $81.8 \%$ & \\
\hline
\end{tabular}


Table 3 Preoperative and postoperative stroposcopic parameters of patients

\begin{tabular}{|c|c|c|c|c|c|}
\hline \multicolumn{2}{|c|}{ Variable } & \multirow{2}{*}{$\begin{array}{c}\text { Preoperative } \\
4\end{array}$} & \multirow{2}{*}{$\begin{array}{c}\begin{array}{c}1 \text { Week } \\
\text { Postoperative. }\end{array} \\
4 \\
\end{array}$} & \multirow{2}{*}{$\begin{array}{c}\begin{array}{c}1 \text { Month } \\
\text { Postoperative. }\end{array} \\
4 \\
\end{array}$} & \multirow{3}{*}{$\begin{array}{c}\text { P value } \\
1\end{array}$} \\
\hline \multirow{2}{*}{ Wave } & Abscent & & & & \\
\hline & Present & 18 & 18 & 18 & \\
\hline \multirow{2}{*}{ Symmetry } & Yes & 0 & 10 & 16 & \multirow{2}{*}{$<0.05$} \\
\hline & No & 18 & 8 & 2 & \\
\hline \multirow[b]{2}{*}{ Amplitude } & Normal & 0 & 10 & 16 & \multirow[b]{2}{*}{$<0.05$} \\
\hline & $\begin{array}{l}\text { Decreased or } \\
\text { increased }\end{array}$ & 18 & 8 & 2 & \\
\hline \multirow{2}{*}{$\begin{array}{c}\text { Non vibratory } \\
\text { segment }\end{array}$} & Present & 10 & 0 & 0 & \multirow{2}{*}{$<0.05$} \\
\hline & Not present & 8 & 18 & 18 & \\
\hline \multirow{2}{*}{ Periodicity } & Periodic & 0 & 15 & 16 & \multirow{2}{*}{$<0.05$} \\
\hline & Aperiodic & 18 & 3 & 2 & \\
\hline
\end{tabular}

Table 4 Duration of closure preoperative, one week and one month postoperative

\begin{tabular}{|c|c|c|c|c|c|c|c|}
\hline & & \multicolumn{2}{|c|}{$\begin{array}{c}\text { Duration } \\
\left(1^{\text {st }} \text { week postoperative. }\right)\end{array}$} & \multirow[t]{2}{*}{$P$ value } & \multicolumn{2}{|c|}{$\begin{array}{c}\text { Duration } \\
\left(1^{\text {st }} \text { month posoperative }\right)\end{array}$} & \multirow[t]{2}{*}{ P Value } \\
\hline & & Half & Open & & Half & Open & \\
\hline \multirow{4}{*}{$\begin{array}{l}\text { Preoperative } \\
\text { duration of } \\
\text { closure }\end{array}$} & \multirow{2}{*}{ Open } & 4 & 6 & \multirow{6}{*}{0.211} & 4 & 6 & \multirow{6}{*}{0.002} \\
\hline & & $40.0 \%$ & $60.0 \%$ & & $40 \%$ & $60 \%$ & \\
\hline & \multirow{2}{*}{$\begin{array}{l}\text { Predominantly } \\
\text { open }\end{array}$} & 8 & 4 & & 12 & 0 & \\
\hline & & $66.7 \%$ & $33.3 \%$ & & $100 \%$ & $0 \%$ & \\
\hline \multirow{2}{*}{\multicolumn{2}{|c|}{ Total }} & 12 & 10 & & 16 & 6 & \\
\hline & & $54.5 \%$ & $45.5 \%$ & & $72.7 \%$ & $27.3 \%$ & \\
\hline
\end{tabular}

Table 5 Pattern of closure preoperative, one week and one month postoperative

\begin{tabular}{|c|c|c|c|c|c|c|c|}
\hline \multirow{2}{*}{\multicolumn{2}{|c|}{$\mathrm{s}$}} & \multicolumn{2}{|c|}{$\begin{array}{c}1 \text { week } \\
\text { Postoperative }\end{array}$} & \multirow[t]{2}{*}{$P$ value } & \multicolumn{2}{|c|}{$\begin{array}{c}1 \text { month } \\
\text { posoperative }\end{array}$} & \multirow[t]{2}{*}{ P Value } \\
\hline & & Complete & $\begin{array}{c}\text { Incomplete (other } \\
\text { configuration) }\end{array}$ & & Complete & $\begin{array}{c}\text { Incomplete (other } \\
\text { configuration) }\end{array}$ & \\
\hline \multirow{4}{*}{ Preop. } & \multirow{2}{*}{ Hourglass } & 4 & 11 & & 7 & 8 & \\
\hline & & $26.7 \%$ & $73.3 \%$ & \multirow{5}{*}{0.166} & $46.7 \%$ & $53.3 \%$ & \multirow{5}{*}{0.015} \\
\hline & \multirow{2}{*}{ irregular } & 4 & 3 & & 7 & 0 & \\
\hline & & $57.1 \%$ & $42.9 \%$ & & $100 \%$ & $0 \%$ & \\
\hline \multirow{2}{*}{\multicolumn{2}{|c|}{ Total }} & 8 & 14 & & 14 & 8 & \\
\hline & & $36.4 \%$ & $63.6 \%$ & & $63.6 \%$ & $63.4 \%$ & \\
\hline
\end{tabular}

Postoperative evaluation showed incomplete removal in 2 cases with vocal cord polyps (11.1\%) and irregular scaring in 2 cases of vocal nodules. Table (2)

Four cases with absent or abnormal mucosal wave were seen after one week and one month postoperatively, symmetry was regained in 10 out of 18 cases after one week and 16 after one month. The amplitude improved into normal in 16 cases at the end of first month. Nonvibratory segment disappeared in 18 cases at the end of first postoperative week. Periodicity is found to be normal in the majority of cases (15 out of 18 at the end of first week and 16 out of 18 at the end of first month).Table (3)

Phase closure "the percentage of time that the vocal cord edges are open and/or closed during a single cycle of vibration" showed no statistically significant one week postoperative change with a $P$ value $=0.211$. However, significant changes were seen one month after surgery with $P$ value 0.002 in regard to duration of closure. Table (4)
Similarly, the changes in regard to the pattern of closure were statistically not significant after one week postoperative with $P$ value $=0.166$. Significant changes occur after one month of surgery with $P$ value $=0.015$. Table (5)

\section{Discussion}

Benign vocal cord lesions are common clinical problems. They are common causes of dysphonia. Their diagnosis and subsequent care can be a complex and important quality-of-life issue to individuals who suffer from this set of disorders. The ability to communicate without dysphonia is important to the population at large for both occupational and social reasons. Removal of lesions, restoring the vibratory function and optimizing the voice are the goals in the treatment of benign vocal cord lesions [8]. Lesions not responsive to voice therapy and / or medical therapy have to be excised surgically. Laryngeal videostroboscopy continues to be the imaging modality of choice by voice clinicians due to its historical use and 61 | Int. J. of Multidisciplinary and Current research, Vol.6 (Jan/Feb 2018) 
ability to efficiently capture many salient vocal cord vibratory characteristics [9] , [10. Using videostroboscopy assessment of the laryngeal functions before and after surgery help to evaluate the effectiveness of the treatment [11].

In our study, $60 \%$ of patients were females and $40 \%$ were males with male to female ratio of 2:3. This figure is against with Banjara et al. [12] , where males predominate (61.6\%) compared with females $(38.4 \%)$ in a ratio of $1.5: 1$ in cases of benign vocal cord lesions, it is also against with Toran K. C. et al [13] and against Guha et al [14] . This may be due to the small size of this study.

In this study, $25 \%$ of patients aged $21-30$ years and $25 \%$ of them aged $31-40$. This figure is consistent with Banjara et al [12] , Guha et al. [14] and Raja et al. [15] . This is due to the voice overactivity in that age group in this society.

In the current study, $50 \%$ of patients were housewives and the second most common job is teaching in 30\% of cases.This figure is consistent with Guha et al. [14] and Raja et al [15].

History of smoking is encountered in $25 \%$ of patients . Guha et al [14] encountered history of smoking in 54\% of patients included in their study.

The most common lesion treated surgically is vocal cord polyp ( $80 \%$ of cases) and this is consistent with George T. et al [16] as the polyp is the most common (64\% of cases). In their study they include the same lesion type; vocal cord polyp, intracordal cyst and vocal cord nodule, as in our study. In our study, the postoperative scar as revealed by laryngeal endoscopy is found in 2 lesions (9\%) and this is also consistent with their study as one case (3\%) develops scar postoperatively and also consistent with Guha et al . [14]

\section{Stroboscopic findings}

In our series, studied parameters the included; wave, nonvibratory segment, symmetry, amplitude , periodicity, duration of closure, and pattern of closure. Similar parameters evaluated by Banjara et al and shown that stroboscopic parameters like glottic closure, amplitude, vocal cord edge, symmetry, periodicity and mucosal wave pattern were studied and statistically significant relationship with different vocal pathologies were obtained [12] . Parameters exhibiting the most reliable judgments (amplitude, vibratory behavior, and edge) were found by Kelley et al [17]. Woo et al in their study of benign lesions of vocal cords observed that the vocal cord edge, glottal configuration, vibratory amplitude, mucosal wave and periodicity are the key factors observed during stroboscopy that affect the quality of the voice [8]. George et al observed the vocal cord for three parameters ; symmetry, mucosal wave and completeness of closure before and after microlaryngeal surgery [16] . Vegienè A. et al, in their study, showed an optimum system of videostroboscopic parameters discriminating normal and pathological voice subgroups with sensitivity
$96.3 \%$ and specificity $100 \%$ included glottal closure and mucosal wave on the affected side. [18]

We found significant changes of stroboscopic parameters ( $p$ value < 0.05) including symmetry, amplitude, nonvibratory segment and periodicity between preoperative and 1 week postoperative but there is no significant changes between 1 week and 1 month postoperative examinations. These result are consistent with Woo et al [8] and George et al) [16] in their studies. Noorzdij et al [19] in their study revealed better postoperative amplitude of cord vibration than preoperative.

Other parameters had been changed differently ; as the wave change, (between preoperative and 1 week postoperative) and (preoperative and 1 month postoperative) insignificantly ( $p$ value $=1$ ). This figure is against George et al where significant change was shown .The pattern of closure was incomplete preoperatively and seen to be complete in 8 patients (36.4\%), which is statistically insignificant ( $p$ value $=0.166$ ) after the first week while after the first month it appeared complete in 14 patients (63.6\%) which is statistically significant ( $p$ value $=0.015$ ). The last result is consistent with George et al. [16].

\section{Conclusion}

Videostroboscopic examination is a useful objective way for assessment of the vocal cord lesions before and after microlaryngeal phonosurgery .Videostroboscopy should be used routinely in assessing patients with benign vocal cord lesions before and after microlaryngeal phonosurgery .

\section{References}

[1]. Gyle E. Woodson. Upper airway anatomy and function. Bailey`s Head Neck surg. Otolaryngol. $5^{\text {th }}$ ed. 2014 61:873877.

[2]. Steven M. Zeitels and Alessandro de Alarcon. History of laryngeal imaging .Laryngeal evaluation indirect laryngoscopy to high speed digital imaging $1^{\text {st }}$ ed. 2010 1:10.

[3]. von Leden H., Moore P. Timcke R. laryngeal vibration measurements of glotticwave: part III. The pathological larynx Arch Otolaryngol Head Nech Surg. 1960 71:16-35.

[4]. von Leden $H$. the electronic synchrono-stroboscopy :its value for practicing laryngologist. Ann Otol Rhinol Laryngol 1961 70:881-893.

[5]. Robert W. Bastin. benign vocal fold mucosal disorder Cumming`s Otolaryngol. Head Neck surg. $6^{\text {th }}$ ed. 2015 61:900.

[6]. Kathrerine A. Kendall .Introduction to videostroboscopy. Laryngeal evaluation indirect laryngoscopy to high speed digital imaging $1^{\text {st }}$ ed. 2010 10:91-100.

[7]. Michael Wareing and Rupert Obholzer. benign laryngeal lesions . Current Diag. and Treat. Otolaryngol. Head Neck surg. $2^{\text {nd }}$ ed. 2008 29:430-434.

[8]. Woo P. , Colton R. and Brewer D. Aerodynamic and stroboscopic findings before and after microlaryngeal phonosurgery. J Voice 1994 6:66-70 . 
[9]. Daryush d Mehta and Robert E Hillman . Current role of stroboscopy in laryngeal imaging . curr. Opin. Otolaryngol. head neck surg. 2012 20(6):429-436.

[10]. Rosen C. A. Stroboscopy as aresearch instrument tool . Laryngosope 2005 115:423-428.

[11]. Woo P. , Colton R. et al . diagnostic value of stroboscopic examination in hoarse patient J Voice 1991 5(3):231-238.

[12]. Banjara H., Mungutwar V., Digvijay Singh , A. Gupta and Surjit Singh .demographic and videostroboscopic assessment of vocal pathologies .Indian J Otolaryngol. Head Neck surg. 2012 64(2):150-157 .

[13].Toran K. C. and Lal B. K. Kathmandu univers. Objective analysis of voice in normal young adult .Med. J. 2010 30(2):185-18

[14]. R. Guha , T. Mondal et al . clinico-demographic trend of benign vocal cord lesions among urban population attending tertiary care institution of kolkata.IOSR J. Dental med Scinces 2015 14(11)64-66.
[15]. Raja Salman K. ,MuKhtar A. Khanand Rauf A. Clinical profile of hoarseness and its management options. Internat J Phonosurg Laryngol. 2012 2(1):23-29.

[16]. George T., Suma S. Mathews et al . Indian J Otolaryngol. outcome analysis of benign vocal cord lesions by videostroboscopy, acaustic analysis and voice handicap index .Head Neck surg. 2007 59:336-340.

[17]. Kelley R. T. ,Colton R. H. and Casper J et al. Evaluation of stroboscopic sigins . J Voice 2011 25:490-495.

[18]. Vegienè A., Pribuišienè R., Šaferis V. ,Uloza V. Quantitative evaluation of video laryngostroboscopy: reliability of the basic parameters. J Voice 2013 27(3):361368 .

[19]. Noorzdij J. P. ,Woo P. Glottal area waveform analysis of benign vocal fold lesions before and after surgery. Ann. Otol. Rhinol. Laryngol. 2000 104:441-446. 